\title{
Safety and outcome of definitive chemoradiotherapy in elderly patients with oesophageal cancer
}

\author{
D Tougeron",', F Di Fiore', S Thureau², N Berbera', I Iwanicki-Caron', H Hamidou², B Paillot' and P Michel' \\ 'Digestive Oncology Unit, Department of Gastroenterology, Rouen University Hospital, Northwest Canceropole, I rue de Germont, Rouen Cedex 7603 I, \\ France; '2Department of Radiotherapy, CRLCC Becquerel, Northwest Canceropole, rue d'Amiens, Rouen 76000, France
}

\begin{abstract}
Little is known about chemoradiotherapy (CRT) in elderly patients with a locally advanced oesophageal cancer (OC). The aim of our study was to evaluate the tolerance and the outcome of elderly patients older than 70 years treated with CRT for a non-metastatic OC. Chemoradiotherapy was based on radiotherapy combined with a cisplatin-based chemotherapy. Clinical complete response (CCR) to CRT was evaluated on upper digestive endoscopy and computed tomography scan 6-8 weeks after CRT completion. One hundred and nine consecutive patients were included. A CCR was observed in 63 patients (57.8\%) and 2-year survival was $35.5 \%$. Adverse events $\geqslant$ grade 3 were observed in 26 (23.8\%) patients. Chemotherapy dose reduction, chemotherapy delays more than I week, and treatment discontinuation were observed in 33 (30.3\%), 45 (4I.3\%), and I7 patients (I5.6\%), respectively. Comorbidity index according to Charlson score was significantly associated with treatment tolerance. In multivariate analysis, a CCR to CRT $(P<0.01)$, a dose of radiotherapy $\geqslant 80 \%(P=0.02)$, and a Charlson score $\leqslant 2(P=0.046)$ were identified as independent prognostic factors of overall survival. These results suggest that CRT could be considered as an effective treatment without major toxicity in elderly patients with OC.

British Journal of Cancer (2008) 99, I586- 1592. doi:I0.1038/sj.bjc.6604749 www.bjcancer.com
\end{abstract}

Published online 28 October 2008

(c) 2008 Cancer Research UK

Keywords: oesophageal cancer; elderly patients; definitive chemoradiotherapy

Management of elderly patients with cancer is a therapeutic challenge. It is well established that cancer occurs primarily in elderly patients, with approximately two-thirds of cancer-related death in the elderly over 60 years and $25 \%$ in patients older than 80 years. Oesophageal cancer (OC) is the eighth most common cancer and the sixth cause of cancer mortality worldwide (Parkin, 2001). In France, approximately $54 \%$ of OC occurs in patients older than 65 years, with $23 \%$ over 75 years (Remontet et al, 2003).

The most relevant treatment modalities in elderly patients with OC remain a subject of debate. Although survival improvement has been observed during the past decade, prognosis of OC has remained significantly influenced by age (Bouvier et al, 2005; Cranea et al, 2007). A recent population-based study including patients with locoregional OC showed a difference in treatment and survival according to age, comorbidity, race, and geographical region (Steyerberg et al, 2007). It has also been reported that elderly patients were less likely to undergo surgery and chemotherapy, which was however partially explained by their comorbidity (Steyerberg et al, 2007; Ruol et al, 2007a). Currently, definitive chemoradiotherapy (CRT) based on the 5-fluorouracilcisplatin (5FU-CDDP) regimen has been considered in curative intent in locally advanced or inoperable non-metastatic OC

\footnotetext{
*Correspondence: Dr D Tougeron, Digestive Oncology Unit, Department of Hepatogastroenterology, Rouen University Hospital, I rue de Germont 7603। Rouen Cedex, France; E-mail: davidtougeron@hotmail.fr Received 16 June 2008; revised 26 September 2008; accepted 30 September 2008; published online 28 October 2008
}

(Kleinberg and Forastiere, 2007; National Cancer Institute recommendations, 2008; Stahl and Oliveira, 2008).

Little is known about the efficacy of CRT in elderly patients with a locally advanced OC. Indeed, data on tolerance and outcome in these patients remain lacking. In the two recent randomised trials that investigated the efficacy of CRT, the mean ages of included patients were 59.1 and 57 years, respectively (Bedenne et al, 2007; Stahl et al, 2005). Moreover, patients up to 70 years were not eligible in the Stahl et al (2005) trial. More recently, in a limited number of 25 patients older than 65 years, Anderson et al (2007) reported that definitive chemoradiation using two cycles of $5 \mathrm{FU}$ plus mitomycin-C associated with $50.4 \mathrm{~Gy}$ radiation could be considered as an active regimen with moderate toxicity.

The aim of our study was to evaluate the safety and the efficacy of CRT in elderly patients older than 70 years treated for a nonmetastatic OC.

\section{PATIENTS AND METHODS}

\section{Patient's inclusion}

All consecutive patients older than 70 years with a non-metastatic OC treated with definitive CRT in Digestive Oncology Unit of Rouen University Hospital between January 1994 and June 2007 were included. The ethical committee approved the procedure and, due to the retrospective analysis with majority of died patients, any patient contentment was necessary. Patient's baseline characteristics (dysphagia, WHO performance status, weight loss, albumine rate, nutritional intervention namely enteral nutrition, and/or 
endoscopic dilation) were collected. Degree of dysphagia was evaluated using the Atkinson (1977) score.

All patients had a histologically proven OC without visceral metastasis at the time of diagnosis and were treated with definitive CRT (Herskovic et al, 1992; Stahl et al, 2005; Bedenne et al, 2007). Patients who had a cancer of the lower and the upper oesophagus associated with an involvement of the coeliac or the sus-clavicular lymph node areas (M1a stage), respectively, were also selected.

We used the Charlson score, which is widely used in comorbidity index, for the analysis of patient's comorbidities. The Charlson score consists of 19 different disease comorbidity categories (coronary artery disease, congestive heart failure, chronic pulmonary disease, peptic ulcer disease, peripheral vascular disease, liver disease, cerebrovascular disease, connective tissue disease, diabetes, dementia, renal disease, prior tumour, and AIDS), each allocated a weight of 1-6 based on the adjusted relative risk of 1-year mortality and summed to provide a total score.

\section{Tumour staging}

The tumour staging was based on the 1983 AJCC staging system according to published recommendations (Coia et al, 2000). Tumour evaluation was based on oesophagoscopy, barium oesophagography, chest and abdominal computed tomography (CT scan) (Bosset et al, 1997), and oesophageal ultrasonography (Tio et al, 1990) when it was feasible. Tumour baseline characteristics (TNM stage, location, length, diameter, and histologic type) were collected. The tumour length was defined by oesophagoscopy \pm barium oesophagography and tumour diameter by endoscopic ultrasound and/or CT scan.

\section{Treatment and CRT regimen}

Patients received a CRT regimen based on the CDDP and 5FU chemotherapy combination described by Herskovic et al (1992) or on the CDDP/irinotecan chemotherapy combination described by Michel et al (2006). The Herskovic CRT regimen was based on four CDDP/5FU chemotherapy courses, which were delivered concomitantly with 50-55 Gy radiotherapy (weeks 1-5). Starting dose regimens were $1000 \mathrm{mg} \mathrm{m}^{-2}$ at days $1-5$ for $5 \mathrm{FU}$ and $75 \mathrm{mg} \mathrm{m}^{-2}$ at day 1 for CDDP. The CRT regimen based on the CDDP/irinotecan chemotherapy combination has been recently reported in a phase II multicentric trial and consisted of eight chemotherapy courses delivered concomitantly with 50-55 Gy radiotherapy (courses five to eight). Starting dose regimens were $60 \mathrm{mg} \mathrm{m}^{-2}$ for irinotecan and $30 \mathrm{mg} \mathrm{m}^{-2}$ for CDDP at each cycle. Radiotherapy was delivered 5 days per week at 1.8 or $2 \mathrm{Gyday}^{-1}$ in both CRT regimens. The target volume of radiotherapy was the macroscopic tumour and enlarged lymph nodes, if any, surrounded by $5-\mathrm{cm}$ proximal and distal margins and a $2-\mathrm{cm}$ radial margin. The target was extended to the inferior cervical area in cases of tumours located above the carina. The specified dose was delivered at the intersection of the central axis of the beams, according to international guidelines.

Twenty-five patients have an initial dose reduction due to their age or comorbidities. Among these patients, the chemotherapy start dose was generally 50 or $75 \%$ of complete dose.

At day 1 of each chemotherapy course, toxicities related to the treatment were evaluated using the National Cancer Institute Common Toxicity Criteria (NCI-CTC, version 2.0). We also noted a delay of chemotherapy and CRT stop for toxicity. Percentage of planned radiotherapy and chemotherapy dose was calculated.

\section{Response to CRT and follow-up}

Patients were considered to have a clinical complete response (CCR) to CRT when no residual tumour was identified on upper digestive endoscopy and when no metastatic disease occurrence was observed on CT scan. This evaluation was performed 6-8 weeks after CRT completion. The follow-up was performed on a clinical basis, with upper digestive endoscopy with biopsy and chest and abdominal CT scans every 3 months. Local recurrence was defined by positive biopsy at upper digestive endoscopy. Salvage surgery in patients without CCR or with local recurrence and absence of metastases were also collected. Follow-up data were updated in December 2007. Among patients alive at 6 months, median follow-up was 20.5 months (6-127 months).

\section{Statistical analysis}

Overall survival was calculated from the date of CRT initiation until the date of death or the date of last follow-up. Survival curve was established using Kaplan-Meier method. Disease-free survival was estimated from the date of the first day of CRT initiation to the time of documented failure (local recurrence or metastasis occurrence) or the date of the last follow-up for those remaining with CCR. Specific survival excluded patients who died of other causes than cancer or treatment. Predictive factors of CCR to CRT were determined by a univariate analysis and further evaluated in multivariate logistic regression analysis. Predictive factors of survival were studied by a univariate analysis and further evaluated in multivariate Cox regression analysis to estimate the hazard ratio (HR) with $95 \%$ confidence interval (CI). Nine predefined baseline variables for the univariate analysis were sex, age, WHO performance status $<2$, initial weight loss $<10 \%$, albumine $\geqslant 30 \mathrm{gl}^{-1}$, Charlson score $\leqslant 2$, dose of cisplatin $\geqslant 80 \%$, dose of radiotherapy $\geqslant 80 \%$, and CCR to CRT. Any variables reaching $P=0.05$ were introduced in multivariate analysis. We also performed an analysis with stratification for age $\geqslant 75$ years $v s$ $<75$ years and patients with or without comorditidies (Charlson index $\leqslant 2 v s>2$ ). All statistical analyses were performed with a two-side significance value of 0.05 . Statistical analysis was performed using the Statview software (Statview for Windows, SAS Institut Inc., version 5.0).

\section{RESULTS}

\section{Patient and tumour characteristics}

One hundred and nine patients over 70 years were analysed. Clinical baseline characteristics are detailed in Table 1. Mean age was $74.4 \pm 3.7$, ranging from 70 to 88 years. There were 38 patients $(34.9 \%)$ aged more than 75 years. Majority of patients $(79.8 \%)$ had a good WHO performance index (0 or 1). Majority of patients had a severe dysphagia $\geqslant 2(70.6 \%)$ and $33.0 \%$ had an initial weight lost $\geqslant 10 \%$.

There were mainly T3 stage tumours $(n=76,69.7 \%)$ and squamous cell carcinoma $(n=77,70.6 \%)$ (Table 2$)$. Majority of tumours were more than $5 \mathrm{~cm}$ in length $(55.0 \%)$, and $29.3 \%$ had a diameter above $3 \mathrm{~cm}$.

Median Charlson score was 1 (range $0-6$ ) (available in 88 patients). Twenty-seven patients $(30.7 \%)$ had Charlson score $\geqslant 2$ and $84 \%$ Charlson score $\geqslant 1$. Majority of patients were autonomous at home (96.6\%). Patients took, on an average, three different medications per day. The prevalence of patients with comorbidities was $84 \%$. Thirteen patients $(14.8 \%)$ had chronic obstructive pulmonary disease, 12 patients $(13.6 \%)$ had a prior or concurrent malignancy, 11 patients $(12.5 \%)$ had diabetes, and 10 patients $(11.4 \%)$ had peripheral vascular disease.

\section{Treatment regimen and tolerance}

Eleven patients $(10.1 \%)$ were started on enteral nutrition and 17 $(15.6 \%)$ on endoscopic dilatation before starting the treatment (Table 3). Ninety-eight patients $(89.9 \%)$ had treatment with 5FU/ CDDP. Sixty-three $(57.8 \%)$ patients received $\geqslant 80 \%$ of cisplatin 
Table I Patient characteristics

\begin{tabular}{|c|c|}
\hline & $n=109$ \\
\hline Age (s.d., min-max) & $74.4 \pm 3.7(70-88)$ \\
\hline Sex ratio (men/women) & $90 / 19$ \\
\hline \multicolumn{2}{|l|}{ WHO performance status (n, \%) } \\
\hline 0 & $24(22.0)$ \\
\hline I & $63(57.8)$ \\
\hline 2 & $22(20.2)$ \\
\hline $\mathrm{WHO}<2$ & $87(79.8)$ \\
\hline \multicolumn{2}{|l|}{ Atkinson dysphagia score (n, \%) } \\
\hline 0 & $5(4.6)$ \\
\hline I & $27(24.8)$ \\
\hline 2 & $55(50.4)$ \\
\hline 3 & $15(13.8)$ \\
\hline 4 & $7(6.4)$ \\
\hline Dysphagia stage $\geqslant 2$ & $77(70.6)$ \\
\hline Initial BMI $\left(\mathrm{kg} \mathrm{m}^{-2}\right.$, s.d.) & $24.9 \pm 6.8$ \\
\hline Initial weight loss (\%, s.d.) & $7.7 \pm 6.6$ \\
\hline Initial weight loss $\geqslant 10 \%(n, \%)$ & $36(33.0)$ \\
\hline Initial albumin $\left(\left.g\right|^{-1}\right.$, s.d. $)$ & $37.7 \pm 5.1$ \\
\hline Creatinine clearance $\left(\mathrm{ml} \mathrm{min}{ }^{-1}\right.$, s.d.) & $73.2 \pm 22.3$ \\
\hline \multicolumn{2}{|l|}{ Charlson score $\mathrm{e}^{\mathrm{a}}$} \\
\hline Median (min-max) & I $(0-6)$ \\
\hline Charlson score $\geqslant 2$ & $27(30.7 \%)$ \\
\hline
\end{tabular}

$\mathrm{BMI}=$ body mass index; $n=$ number of patients; s.d. $=$ standard deviation. ${ }^{\mathrm{a}}$ Available for 88 patients.

planned dose and $85(78 \%)$ received $\geqslant 80 \%$ of radiotherapy planned dose. Sixty-two patients (56.9\%) experienced adverse effects $\geqslant$ grade 2 , mainly vomiting and neutropaenia. Twenty-four patients experienced grade 3 toxicity $(22.0 \%)$, four an adverse effect grade 4, with one toxic death (neutropaenia with peritonitis caused by diverticular sigmoiditis). These adverse events conducted to a treatment-related hospitalisation in 18 patients $(16.5 \%)$. Dose reduction for toxicity was performed in 33 patients $(30.3 \%)$, a chemotherapy delay of more than 1 week was required in 45 patients $(41.3 \%)$, and CRT discontinuation was necessary in 17 patients $(15.6 \%)$. Finally, 42 patients $(38.5 \%)$ completed the planned CRT regimen.

\section{Response to CRT, survival and outcome}

Median overall survival was $15.2 \pm 2.8$ months and disease-free survival was $8.3 \pm 7.3$ months (Figure 1) (Table 4). Two-year and 5 -year survival rates were $35.5 \%$ (95\% CI: $30.8-40.2$ ) and $12.8 \%$ (95\% CI: $9.2-16.4$ ), respectively. Distant metastasis occurred in 31 patients $(28.4 \%)$ during follow-up. Cancer was the cause of death in 73 patients $(80.2 \%)$ among the patients who died $(n=91)$.

A CCR to CRT was observed in 63 patients $(57.8 \%)$, and 26 $(23.8 \%)$ of them had no recurrence at follow-up (median follow-up was 20.5 months and eight patients were lost to follow-up). Median overall survival in patients with CCR was $27.2 \pm 5.1$ months as compared with $6.0 \pm 2.5$ months in non-responders $(P<0.01)$ (Figure 2). Among responders to CRT, 21 patients (33.3\%) had a local recurrence, with a median time of $13.4 \pm 2.2$ months. Two patients with local recurrence underwent surgery but the majority of patients were treated by oesophageal stent $(n=9)$, chemotherapy $(n=4)$, or the best supportive care $(n=6)$. In non-responder patients to CRT, a salvage surgery was performed in five patients. One patient died after surgery and three had local or metastasis recurrence. Patients without CCR to CRT and surgical
Table 2 Tumour characteristics

$n=109$

$\begin{array}{lc}\text { TNM stage (n, \%) } & \\ \text { TINO } & 2(I .8) \\ \text { TINI } & 0 \\ \text { T2NO } & 13(11.9) \\ \text { T2NI } & 5(4.6) \\ \text { T3NO } & 32(29.3) \\ \text { T3NI } & 44(40.4) \\ \text { T4NO } & 0 \\ \text { T4NI } & 2(1.8) \\ \text { Coeliac lymph nodes MIa } & 6(5.5) \\ \text { Sus-clavicular lymph nodes Mla } & 0 \\ \text { Unknown (MO) } & 5(4.6) \\ & \\ \text { Tumoral stage (n, \%) } & \\ \text { Stage I } & 2(1.8) \\ \text { Stage II } & 50(45.9) \\ \text { Stage III } & 46(42.2) \\ \text { Stage IV (MIa) } & 6(5.5) \\ \text { Unknown (MO) } & 5(4.6)\end{array}$

Oesophagus tumoral location ( $\mathrm{n}, \%)$

Lower one-third

$52(47.7)$

Middle one-third

$36(33.3)$

Upper one-third

$21(19.3)$

Mean tumour length $(\mathrm{cm}, \mathrm{s.d}$ )

$5.2 \pm 2.1$

$60(55.0)$

$2.7 \pm 1.2$

$32(29.3)$

Mean tumour diameter ( $\mathrm{cm}, \mathrm{s} . \mathrm{d}$.)

Mean tumour diameter $\geqslant 3 \mathrm{~cm}(n, \%)$

Histological type ( $n, \%)$

Squamous cell carcinoma

Adenocarcinoma

$28(25.7)$

Indifferentiated

$4(3.7)$

Histological differentiation (n, \%)

Well differentiated

$26(23.8)$

Fairly differentiated

$22(20.2)$

Poorly differentiated

$12(11.0)$

Indifferentiated

$5(4.6)$

Unknown

$44(40.4)$

CT $\operatorname{scan}(n, \%)$

Echoendoscopy (n, \%)

$n=$ number of patients; s.d. = standard deviation.

contraindications were treated by oesophageal stent $(n=7)$, chemotherapy $(n=3)$, or the best supportive care.

\section{Prognostic factors of CCR to CRT and overall survival}

Predictive factors of a CCR to CRT in univariate analysis were a WHO performance status $<2(P=0.02)$, an initial weight loss $<10 \%(P=0.01)$, a dose of cisplatin $\geqslant 80 \%(P<0.01)$, and a dose of radiotherapy $\geqslant 80 \% \quad(P<0.01) \quad$ (Table 5). In multivariate analysis, adjusted for sex and age, a dose of radiotherapy $\geqslant 80 \%$ (HR $=12.1,95 \%$ CI: $3.0-49.4 ; P<0.01)$ and a dose of cisplatin $\geqslant 80 \%(\mathrm{HR}=3.4,95 \% \mathrm{CI}: 1.3-9.1 ; P=0.01)$ were identified as independent prognostic factors of CCR.

Predictive factors of overall survival in univariate analysis were a CCR to CRT $(P<0.01)$, a WHO performance status $<2$ $(P<0.01)$, an initial weight loss $<10 \%(P=0.03)$, a dose of cisplatin $\geqslant 80 \% \quad(P=0.03)$, a dose of radiotherapy $\geqslant 80 \%$ $(P<0.01)$, and a Charlson score $\leqslant 2(P=0.02)$. T stage and age $<$ or $>75$ years were not predictive factors of overall survival in univariate analysis ( $\mathrm{T}$ stage, $P=0.85$ and age $<$ or $>75$ years, 
Table 3 Treatment regimen and toxicity

\begin{tabular}{|c|c|}
\hline & $n=109$ \\
\hline \multicolumn{2}{|l|}{ Treatment before CRT initiation (n, \%) } \\
\hline Enteral nutrition by nasogastric tube & $7(6.4)$ \\
\hline Enteral nutrition by stomy & $4(3.7)$ \\
\hline Endoscopic dilation & $17(15.6)$ \\
\hline Oesophageal stent & $2(1.8)$ \\
\hline \multicolumn{2}{|l|}{ Chemotherapy regimen $(\mathrm{n}, \%)$} \\
\hline Irinotecan/CDDP & $10(9.2)$ \\
\hline 5-FU/CDDP & $98(89.9)$ \\
\hline Other & I (0.9) \\
\hline \multicolumn{2}{|l|}{ Mean chemotherapy course } \\
\hline Irinotecan/CDDP regimen & $6.2 \pm 2.6$ \\
\hline 5-FU/CDDP regimen & $3.6 \pm 1.8$ \\
\hline Mean radiotherapy dose (grays) & $49.0 \pm 13.9$ \\
\hline \multicolumn{2}{|l|}{ Treatment dose } \\
\hline$\%$ of cisplatin planned dose $(\%$, s.d. $)$ & $69.0 \pm 27.4$ \\
\hline$\%$ of cisplatin planned dose $\geqslant 80 \%$ & $63(57.8)$ \\
\hline$\%$ of radiotherapy planned dose $(\%$, s.d. $)$ & $89.8 \pm 22.9$ \\
\hline$\%$ of radiotherapy planned dose $\geqslant 80 \%$ & $85(78.0)$ \\
\hline Patients with adverse effects $\geqslant$ grade $2(n, \%)$ & $62(56.9)$ \\
\hline Patients with treatment delay more than I week $(n, \%)$ & $45(41.3)$ \\
\hline Patients with treatment discontinuation $(n, \%)$ & $17(15.6)$ \\
\hline Patients with chemotherapy dose reduction ( $n, \%)$ & $58(53.2)$ \\
\hline Due to adverse events & $33(30.3)$ \\
\hline Due to age & $25(22.9)$ \\
\hline \multicolumn{2}{|l|}{ Patients with treatment toxicity $\geqslant$ grade $2(\mathrm{n}, \%)$} \\
\hline Neutropaenia & $27(24.8)$ \\
\hline Vomiting & $16(14.7)$ \\
\hline Mucitis & $15(13.8)$ \\
\hline Infection & $13(11.9)$ \\
\hline Diarrhoea & $8(7.3)$ \\
\hline Renal insufficiency ${ }^{\mathrm{a}}$ & $6(5.5)$ \\
\hline
\end{tabular}

CDDP/irinotecan regimen $=$ cisplatin and irinotecan chemotherapy combination; $\mathrm{CRT}=$ chemoradiotherapy; $\mathrm{n}=$ number of patients; s.d. = standard deviation; 5-FU/ CDDP regimen $=$ cisplatin and 5 -fluorouracil chemotherapy combination. ${ }^{a}$ Diminution of creatinine clearance under $50 \mathrm{ml} \mathrm{min}^{-1}$ after starting of chemotherapy.

$P=0.15)$. In multivariate analysis, adjusted for sex and age, a CCR to CRT $(27.2 \pm 5.1$ months in responders vs $6.0 \pm 2.5$ months in non-responders; $\mathrm{HR}=4.9,95 \% \mathrm{CI}: 2.5-9.5 ; P<0.01$ ), a dose of radiotherapy $\geqslant 80 \%(21.2 \pm 7.0$ months if dose of radiotherapy $\geqslant 80 \%$ vs $3.3 \pm 1.0$ months if dose of radiotherapy $<80 \%$; $\mathrm{HR}=2.3,95 \% \mathrm{CI}: 1.3-4.2 ; P=0.02$ ), and a Charlson score $\leqslant 2$ $(13.9 \pm 3.6$ months if Charlson score $\leqslant 2$ vs $4.1 \pm 2.6$ months if Charlson score $>2$; $\mathrm{HR}=2.1,95 \% \mathrm{CI}$ : $1.0-4.5 ; P=0.046$ ) were identified as independent prognostic factors of overall survival.

\section{Factors that influence treatment tolerance}

Age $\geqslant 75$ years was associated with worse creatinine clearance $(P<0.01)$ and more chemotherapy dose reduction at treatment onset due to age $(P<0.01)$, but this had no influence on total CRT dose, adverse events, CCR to RCT, or overall survival. Patient with a dose reduction at treatment onset was older but age did not influence chemotherapy dose. This result was probably explained by the fact that the patient with a dose reduction up front has a secondary increase of chemotherapy dose if the tolerance was good (nine patients).

Charlson score $\leqslant 2$ vs $>2$ did not influence adverse events, chemotherapy delay, CRT dose, or CCR to CRT, but only overall

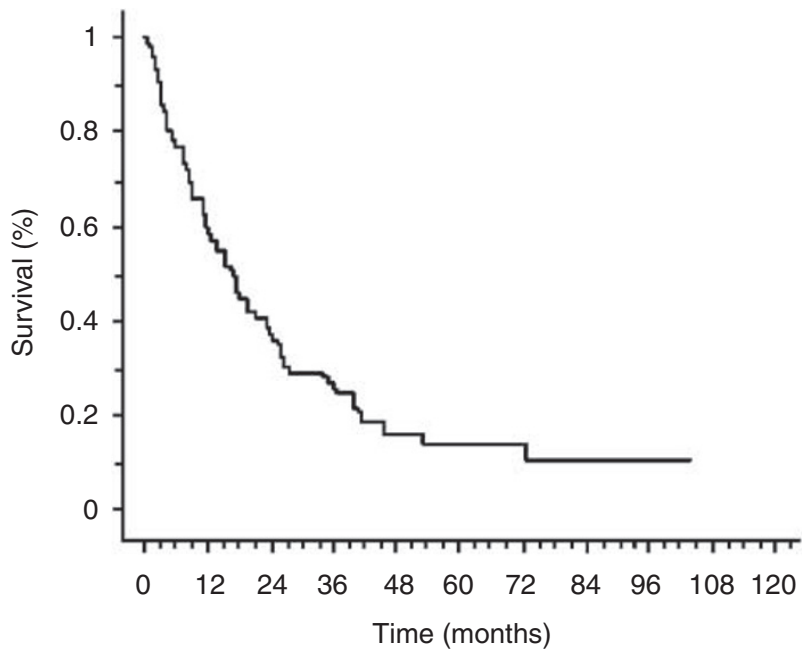

Patients at risk

$\begin{array}{lllllllllll}109 & 62 & 34 & 21 & 11 & 7 & 4 & 2 & 2 & 1 & 0\end{array}$

Figure I Overall survival. The median overall survival was $15.2 \pm 2.8$ months.

Table 4 Patients' outcome and survival

\begin{tabular}{lc}
\hline & $\mathbf{n}=\mathbf{1 0 9}$ \\
\hline Outcome in all patients & $n=109$ \\
CCR to CRT (n, \%) & $63(57.8)$ \\
Overall survival (months, s.d.) & $15.2 \pm 2.8$ \\
Specific survival & $19.5 \pm 1.9$ \\
Disease-free survival (months, s.d.) & $8.3 \pm 7.3$ \\
Metastasis occurrence ( $n, \%)$ & $31(28.4)$ \\
Mean time of metastasis occurrence (months, s.d.) & $15.4 \pm 3.9$ \\
& \\
Outcome in patients with CCR & $n=63$ \\
Local recurrence (n, \%) & $21(33.3)$ \\
Mean time to local recurrence (months, s.d.) & $13.4 \pm 2.2$ \\
Metastasis occurrence (n, \%) & $21(33.3)$ \\
Mean time to metastasis occurrence (months, s.d.) & $17.4 \pm 4.7$ \\
Median survival (months, s.d.) & $27.2 \pm 5.1$ \\
Patient without recurrence & $26(23.8 \%)$ \\
& \\
Outcome in non-responders to CRT & $n=46$ \\
Median survival (months, s.d.) & $6.0 \pm 2.5$ \\
Causes of death & $n=91$ \\
Cancer & $73(80.2 \%)$ \\
Treatment & $2(2.2 \%)$ \\
Others & $14(15.4 \%)$ \\
\hline
\end{tabular}

$\mathrm{CCR}=$ clinical complete response; $\mathrm{CRT}=$ chemoradiotherapy; $n=$ number of patients; s.d. = standard deviation

survival. Nevertheless, patients with Charlson score $\geqslant 1$ experienced more adverse events grade $\geqslant 2(76.5$ vs $51.2 \% ; P=0.01)$ and chemotherapy delay (66.7 vs $39.5 \%$; $P=0.02$ ).

\section{DISCUSSION}

This study suggested that definitive CRT in elderly patients with an OC was an effective treatment without a major increase in adverse events. Moreover, our results showed that CRT in elderly patients produced a similar response rate and overall survival as usually reported in younger patients treated with the same regimen. These findings suggest that a treatment based on a CRT regimen may be discussed in elderly patients. Improvements in general health care 
and increased life expectancy have resulted in more elderly patients with an OC. At 75 years of age, life expectancy was more than 10 years (Arias, 2006). Therefore, if there are no major comorbidities, elderly patients with OC should benefit from curative treatment.

Definitive CRT is considered as a feasible non-surgical treatment for patients with a locally advanced OC with approximately $50-65 \%$ CCR rate, 17-26 months of median overall survival, and

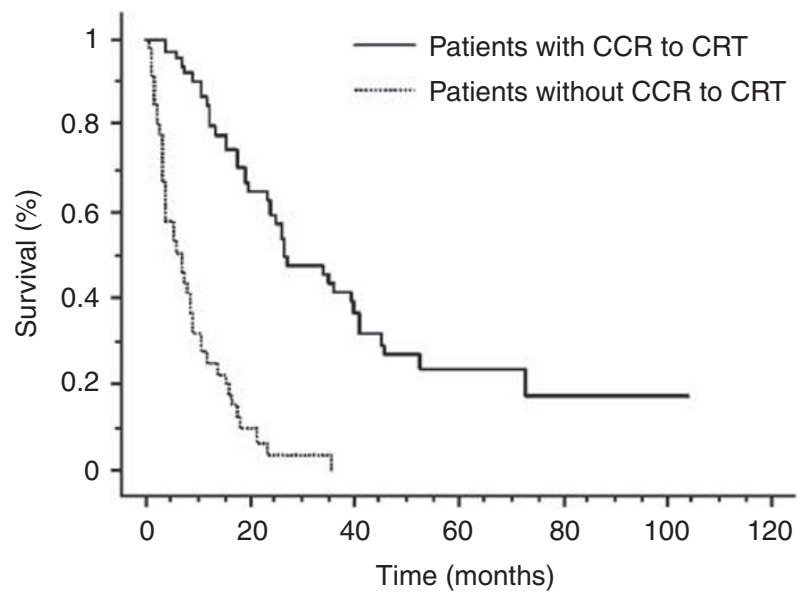

Figure 2 Overall survival in responders and non-responders to CRT. The median overall survival was $27.2 \pm 5.1$ months in responder patients as compared with $6.0 \pm 2.5$ months in non-responder patients $(P<0.01)$.
30-40\% 2-year survival rate (Minsky et al, 1999; Ohtsu et al, 1999; Coia et al, 2000; Seitz et al, 2000; Stahl et al, 2005; Michel et al, 2006; Di Fiore et al, 2006a; Bedenne et al, 2007). Interestingly, our results in elderly patients were relatively close to those reported in these series, with a CCR to CRT of $57.8 \%$ and a 2 -year overall survival rate of $35.5 \%$. However, overall median survival in our study (15.2 months) was slightly lower as compared with that reported in previous randomised trials. These results were strictly similar to those published by our group on series including non-selected patients with an oesophageal carcinoma treated with the same CRT regimens (Michel et al, 2006; Di fiore et al, 2006a, b; Tougeron et al, 2008). Indeed, the mean age of patients ranged from 39 to 88 years in these series and we found that the complete response to CRT was $50-80 \%$ and the overall survival was $16-20$ months as in this study in elderly patients. Although age and comorbidity were associated with higher difficulties encountered during treatment, no significant association was found between these factors and survival in our study. Moreover, the difference in median overall survival could be partially explained by a selection bias in these prospective trials, whereas our study possibly reflected the outcome of non-selected patients. In a recent study, predictive factors of prognosis in locally advanced OC from the randomised FFCD 9102 trial in the multivariate analysis were age more than 65 years, inability to ingest solid food, and the presence of more than three neoplastic coeliac lymph nodes on endoscopic ultrasonography (Burtin et al, 2008).

Anderson et al (2007) reported significant results from a single institution experience of chemoradiation in 25 elderly patients older than 65 years with OC. On the basis of a median follow-up of 32 months, the CCR rate was $68 \%$ and the 2 -year survival rate was

Table 5

Univariate and multivariate analysis of CCR to CRT and overall survival

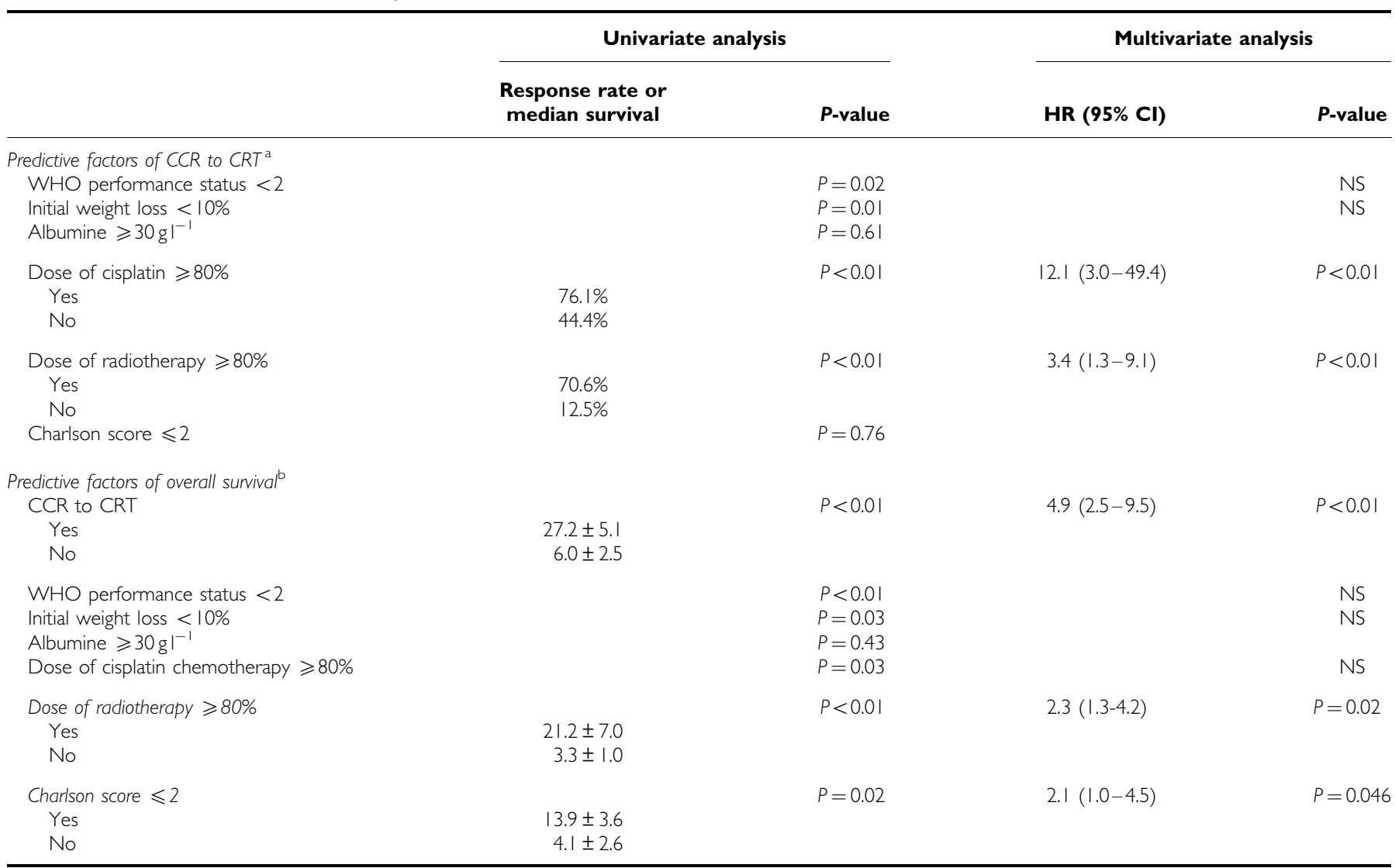

$\mathrm{CCR}=$ clinical complete response; $\mathrm{Cl}=$ confidence interval; $\mathrm{CRT}=$ chemoradiotherapy; HR = hazard ratio; NS, nonsignificant. ${ }^{a}$ Multivariate logistic regression analysis adjusted on sex and age. 'Multivariate Cox regression analysis adjusted on sex and age.

$\mathrm{CCR}=$ clinical complete response; CRT = chemoradiotherapy. 
$64 \%$ (95\% CI: $45-83$ ) in this study. The overall survival was very good probably because there was a careful selection of patients using Charlson score and data were only available on 25 patients with a very significant CI for survival rate. Different findings were found in the Takeuchi et al (2007) study in which results of CRT based on 5FU/CCDP and $60 \mathrm{~Gy}$ of radiation were compared between 33 elderly patients $v s 145$ non-elderly. In fact, a significant worse survival and higher CRT discontinuation and toxicity were reported in elderly. These contradictory results strongly support that more data on larger population, as in our study, are required to accurately estimate the safety and efficacy of the CRT approach in an elderly population. Local recurrence and metastasis occurrence in our study were in accordance with randomised trials (Minsky et al, 1999; Seitz et al, 2000; Bedenne et al, 2007).

Salvage oesophagectomy has been reported in a small group of elderly patients who did not respond to CRT. Five patients underwent surgery in our series and only one in the study of Anderson et al (2007). Death due to post-operative complications occurred in one patient in our study and also in one patient in the Anderson et al (2007) study. Although a significant improvement has been obtained in post-operative resuscitation, oesophagectomy for OC remains associated with significant morbidity and mortality rates. In this context, surgical approach in patients older than 70 years with OC is still debated because of potentially higher postoperative complication rates (Poon et al, 1998; Law et al, 2004; Moskovitz et al, 2006). On the basis of a population of 421 patients with intrathoracic squamous cell carcinoma treated with surgical resection, Law et al (2004) found that age was significantly associated with pulmonary complications and hospital mortality. In a single institution study on 751 patients including 31 patients older than 80 years, Moskovitz et al (2006) reported that postoperative death and hospital length of stay were significantly worse in elderly patients, independently of comorbidity. In contrast, Ruol et al $(2007 \mathrm{~b}, \mathrm{c})$ recently showed similar short- and long-term postoperative outcomes in elderly patients as compared with younger patients. This difference could be due to difference in surgical and resuscitation experience between centres. Median survival after oesophagectomy remains poor in elderly patients, ranging from 6 to 27 months, with major post-operative mortality ranging from 4.7 to $7.2 \%$ (Thomas et al, 1996; Poon et al, 1998; Sabel et al, 2002; Internullo et al, 2008).

In our study, the planned treatment was achieved in only $38.5 \%$ of patients, and $53.2 \%$ of them required dose adjustment. However, grade 4 toxicity was observed only in three patients $(2.7 \%)$, with two treatment-related deaths (1.8\%). In the Anderson et al (2007) study, $88 \%$ of patients completed the planned CRT, grade 4 toxicity occurred in $16 \%$, and no treatment-related deaths were observed. Moreover, severe adverse events (grade 3 or 4 ) were observed in $23.8 \%$ of patients in this study and $31 \%$ of patients randomised in the definitive CRT arm of FFCD 9102 study. Chemoradiotherapy tolerance in 'selected' elderly patients with an OC was acceptable as compared with younger patients, but a dose reduction was frequently necessary due to adverse events. Age $\geqslant 75$ years had no influence on adverse events. These results underlined that age criteria alone is not sufficient for guidance of therapy and that better characterisation of patients with Charslon score, for example, may be helpful for decision making. 5-Fluorouracil tolerance was the same in the elderly and younger patients (Popescu et al, 1999). Moreover, a recent study on patients with an advanced oesophagogastric adenocarcinoma suggested that cisplatin-based chemotherapy toxicities did not increase with age (Trumper et al, 2006). In patients with other cancers (rectum, lung, or head and neck cancers) treated with concomitant CRT, the same results were observed. In these elderly patients treated with CRT for other tumours, no major toxicity was observed with similar survival rates than in younger patients (Airoldi et al, 2004; Pasetto et al, 2006; Semrau et al, 2007).

The main reported predictive factors of response to CRT and overall survival were WHO performance status, nutritional status, treatment dose, and TNM stage (Coia et al, 2000; Polee et al, 2003; Rohatgi et al, 2005; Di Fiore et al, 2006a). No major difference was found, in our multivariate analysis, in predictive factors of CCR to CRT and survival in elderly patients. Although age and Charlson score were associated with nutritional impairment and a greater chemotherapy dose reduction, our analysis also underlined that the success rate of CRT in OC was not dependant on age.

In conclusion, our results showed that definitive CRT could be considered as an effective treatment with no significant toxicity in elderly patients with OC.

\section{ACKNOWLEDGEMENTS}

We are most grateful to Richard Medeiros, Rouen University Hospital Medical Editor, for editing the paper.

\section{Conflict of interest}

The authors confirm that there is no conflict of interest.

\section{REFERENCES}

Airoldi M, Cortesina G, Giordano C, Pedani F, Gabriele AM, Marchionatti S, Bumma C (2004) Postoperative adjuvant chemoradiotherapy in older patients with head and neck cancer. Arch Otolaryngol Head Neck Surg 130: $161-166$

Anderson SE, Minsky BD, Bains M, Hummer A, Kelsen D, Ilson DH (2007) Combined modality chemoradiation in elderly oesophageal cancer patients. Br J Cancer 96: $1823-1827$

Arias E (2006) United States Life Tables, 2003. National vital statistics reports; vol 54 no 14 National Center for Health Statistics: Hyattsville, MD. Available from: http://www.cdc.gov/nchs/data/nvsr/nvsr54/nvsr54_14.pdf

Atkinson M (1977) Diseases of the alimentary system. Dysphagia. BMJ 1: 91-93

Bedenne L, Michel P, Bouche O, Milan C, Mariette C, Conroy T, Pezet D, Roullet B, Seitz JF, Herr JP, Paillot B, Arveux P, Bonnetain F, Binquet C (2007) Chemoradiation followed by surgery compared with chemoradiation alone in squamous cancer of the esophagus: FFCD 9102. J Clin Oncol 25: $1160-1168$

Bosset JF, Gignoux M, Triboulet JP, Tiret E, Mantion G, Elias D, Lozach P, Ollier JC, Pavy JJ, Mercier M, Sahmoud T (1997) Chemoradiotherapy followed by surgery compared with surgery alone in squamous cell cancer of the œsophagus. N Engl J Med 337: 161-167

Bouvier AM, Launoy G, Lepage C, Faivre J (2005) Trends in the management and survival of digestive tract cancers among patients aged over 80 years. Aliment Pharmacol Ther 22: 233-241

Burtin $\mathrm{P}$, Bouché $\mathrm{O}$, Giovannini $\mathrm{M}$, Pelletier $\mathrm{M}$, Conroy T, Ruget $\mathrm{O}$, Arsène D, Milan C, Bedenne L (2008) Endoscopic ultrasonography is an independent predictive factor of prognosis in locally advanced esophageal cancer. Results from the randomized FFCD 9102 study from the Fédération Francophone de Cancérologie Digestive. Gastroenterol Clin Biol 32: 213-220

Coia LR, Minsky BD, Berkey BA, John MJ, Haller D, Landry J, Pisansky TM, Willett CG, Hoffman JP, Owen JB, Hanks GE (2000) Outcome of patients receiving radiation for cancer of the esophagus: results of the 1992-1994 patterns of care study. J Clin Oncol 18: 455-462

Cranea LM, Schaapveldb M, Visserc O, Louwmand MW, Plukkera JT, van Dama JM (2007) Oesophageal cancer in the Netherlands: increasing incidence and mortality but improving survival. Eur $J$ cancer 43: $1445-1451$ 
Di Fiore F, Lecleire S, Galais MP, Rigal O, Vié B, David I, Hamidou H, Paillot B, Jacob JH, Michel P (2006b) Impact of radiation schedule and chemotherapy duration in definitive chemoradiotherapy regimen for esophageal cancer. Gastroenterol Clin Biol 30: 845-851

Di Fiore F, Lecleire S, Rigal O, Galais MP, Ben Soussan E, David I, Paillot B, Jacob JH, Michel P (2006a) Predictive factors of survival in patients treated with definitive chemoradiotherapy for squamous cell esophageal carcinoma. World J Gastroenterol 12: 4185-4190

Herskovic A, Martz K, al-Sarraf M, Leichman L, Brindle J, Vaitkevicius V, Cooper J, Byhardt R, Davis L, Emami B (1992) Combined chemotherapy and radiotherapy compared with radiotherapy alone in patients with cancer of the esophagus. $N$ Engl J Med 326: 1593-1598

Internullo E, Moons J, Nafteux P, Coosemans W, Decker G, De Leyn P, Van Raemdonck D, Lerut T (2008) Outcome after esophagectomy for cancer of the esophagus and GEJ in patients aged over 75 years. Eur Cardiothorac Surg 33: 1096-1104

Kleinberg L, Forastiere AA (2007) Chemoradiation in the management of esophageal cancer. J Clin Oncol 25: 4110-4117

Law S, Wong KH, Kwok KF, Chu KM, Wong J (2004) Predictive factors for postoperative pulmonary complications and mortality after esophagectomy for cancer. Ann Surg 240: $791-800$

Michel P, Adenis A, Fiore FD, Boucher E, Galais MP, Dahan L, Mirabel X, Hamidou H, Raoul JL, Jacob JH, Hellot MF, Prod'homme S, Paillot B (2006) Induction cisplatin - irinotecan followed by concurrent cisplatinirinotecan and radiotherapy without surgery in oesophageal cancer: multicenter phase II FFCD trial. Br J Cancer 95: 705-709

Minsky BD, Neuberg D, Kelsen DP, Pisansky TM, Ginsberg RJ, Pajak T, Salter M, Benson III AB (1999) Final report of Intergroup Trial 0122 (ECOG PE-289, RTOG 90-12): phase II trial of neoadjuvant chemotherapy plus concurrent chemotherapy and high-dose radiation for squamous cell carcinoma of the esophagus. Int J Radiat Oncol Biol Phys 43: $517-523$

Moskovitz AH, Rizk NP, Venkatraman E, Bains MS, Flores RM, Park BJ, Rusch VW (2006) Mortality increases for octogenarians undergoing esophagogastrectomy for esophageal cancer. Ann Thorac Surg 82: $2031-2036$

National Cancer Institute recommendations (2008) http://www.cancer.gov/ cancertopics/pdq/treatment/esophageal/HealthProfessional/page9

Ohtsu A, Boku N, Muro K, Chin K, Muto M, Yoshida S, Satake M, Ishikura S, Ogino T, Miyata Y, Seki S, Kaneko K, Nakumura A (1999) Definitive chemoradiotherapy for T4 and/or M1 lymph node squamous cell carcinoma of the esophagus. J Clin Oncol 17: 2915-2921

Parkin DM (2001) Global cancer statistics in the year 2000. Lancet Oncol 2: $533-543$

Pasetto LM, Friso ML, Pucciarelli S, Basso U, Falci C, Bortolami A, Toppan P, Agostini M, Rugge M, Serpentini S, Nitti D, Monfardini S (2006) Rectal cancer neoadjuvant treatment in elderly patients. Anticancer Res 26: $3913-3923$

Polee MB, Hop WCJ, Kok TC, Eskens FALM, Van der Burg MEL, Splinter TA, Siersema PD, Tilanus HW, Stoter G, van der Gaast A (2003) Prognostic factors for survival in patients with advanced oesophageal cancer treated with cisplatin-based combination chemotherapy. $\mathrm{Br} J$ Cancer 89: 2045 - 2050

Poon RT, Law SY, Chu KM, Branicki FJ, Wong J (1998) Esophagectomy for carcinoma of the esophagus in the elderly: results of current surgical management. Ann Surg 227: 357-364

Popescu RA, Norman A, Ross PJ, Parikh B, Cunningham D (1999) Adjuvant or palliative chemotherapy for colorectal cancer in patients 70 years or older. J Clin Oncol 17: 2412-2418

Remontet L, Estève J, Bouvier AM, Grosclaude P, Launoy G, Menegoz F, Exbrayat C, Tretare B, Carli PM, Guizard AV, Troussard X, Bercelli P, Colonna M, Halna JM, Hedelin G, Macé-Lesec'h J, Peng J, Buemi A, Velten M, Jougla E, Arveux P, Le Bodic L, Michel E, Sauvage M, Schvartz
C, Faivre J (2003) Cancer incidence and mortality in France over the period 1978-2000. Rev Epidemiol Sante Publique 51: 3-30

Rohatgi P, Swisher SG, Correa AM, Wu TT, Liao Z, Komaki R, Walsh GL, Vaporciyan AA, Rice DC, Roth JA, Ajani JA (2005) Characterization of pathologic complete response after preoperative chemoradiotherapy in carcinoma of the esophagus and outcome after pathologic complete response. Cancer 104: $2365-2372$

Ruol A, Portale G, Castoro C, Merigliano S, Cavallin F, Battaglia G, Michieletto S, Ancona E (2007a) Management of esophageal cancer in patients aged over 80 years. Eur J Cardiothorac Surg 32: 445-448

Ruol A, Portale G, Castoro C, Merigliano S, Cagol M, Cavallin F, Chiarion Sileni V, Corti L, Rampado S, Costantini M, Ancona E (2007c) Effects of neoadjuvant therapy on perioperative morbidity in elderly patients undergoing esophagectomy for esophageal cancer. Ann Surg Oncol 14: $3243-3250$

Ruol A, Portale G, Zaninotto G, Cagol M, Cavallin F, Castoro C, Sileni VC, Alfieri R, Rampado S, Ancona E (2007b) Results of esophagectomy for esophageal cancer in elderly patients: age has little influence on outcome and survival. J Thorac Cardiovasc Surg 133: 1186-1192

Sabel MS, Smith JL, Nava HR, Mollen K, Douglass HO, Gibbs JF (2002) Esophageal resection for carcinoma in patients older than 70 years. Ann Surg Oncol 9: 210-214

Seitz JF, Milan C, Giovannini M, Dumas F, Cauvin JM, Conroy T, Francois E, Renard P, Votte-Lambert A, Paillot B, Bedenne L (2000) Concurrent concentrated radio-chemotherapy of epidermoid cancer of the esophagus. Long-term results of a phase II national multicenter trial in 122 nonoperable patients (FFCD 8803). Gastroenterol Clin Biol 24: 201-210

Semrau S, Bier A, Thierbach U, Virchow C, Ketterer P, Klautke G, Fietkau R (2007) 6-year experience of concurrent radiochemotherapy with vinorelbine plus a platinum compound in multimorbid or aged patients with inoperable non-small cell lung cancer. Strahlenther Onkol 183: $30-35$

Stahl M, Stuschke M, Lehmann N, Meyer HJ, Walz MK, Seeber S, Klump B, Budach W, Teichmann R, Schmitt M, Schmitt G, Franke C, Wilke H (2005) Chemoradiation with and without surgery in patients with locally advanced squamous cell carcinoma of the esophagus. J Clin Oncol 23: $2310-2317$

Stahl M, Oliveira J, ESMO Guidelines Working Group (2008) Esophageal cancer: ESMO clinical recommendations for diagnosis, treatment and follow-up. Ann Oncol 19(Suppl 2): ii21 - ii22

Steyerberg EW, Neville B, Weeks JC, Earle C (2007) Referral patterns, treatment choices, and outcomes in locoregional esophageal cancer: a population-based analysis of elderly patients. J Clin Oncol 25: 2389-2396

Takeuchi S, Ohtsu A, Doi T, Kojima T, Minashi K, Mera K, Yano T, Tahara M, Muto M, Nihei K (2007) A retrospective study of definitive chemoradiotherapy for elderly patients with esophageal cancer. $\mathrm{Am} \mathrm{J}$ Clin Oncol 30: 607-611

Thomas P, Doddoli C, Neville P, Pons J, Lienne P, Giudicelli R, Giovannini M, Seitz JF, Fuentes P (1996) Esophageal cancer resection in the elderly. Eur J Cardiothorac Surg 10: 941 -946

Tio TL, Coene PP, Den Hartog Jager FC, Tytgat GN (1990) Preoperative TNM classification of esophageal carcinoma by endosonography. Hepatogastroenterol 37: 376-381

Tougeron D, Di Fiore F, Hamidou H, Rigal O, Paillot B, Michel P (2008) Response to definitive chemoradiotherapy and survival in patients with an oesophageal adenocarcinoma $v s$ squamous cell carcinoma: a matchedpair analysis. Oncology 73: 328-334

Trumper M, Ross PJ, Cunningham D, Norman AR, Hawkins R, Seymour M, Harper P, Iveson T, Nicolson M, Hickish T (2006) Efficacy and tolerability of chemotherapy in elderly patients with advanced oesophagogastric cancer: a pooled analysis of three clinical trials. Eur J Cancer 42: $827-834$ 